\title{
Economical Design of a Two-Axis Tracking System for Solar Collectors
}

\author{
Amr E. Gaafar*, Ahmed F. Zobaa ${ }^{\dagger}$ \\ *Sheffield Hallam University, United Kingdom, agaafar@theiet.org \\ ${ }^{+}$Brunel University London, United Kingdom,azobaa@theiet.org
}

Keywords: Solar, Renewable, Two-Axis Tracking, Parabolic.

\begin{abstract}
Renewable energy is an infinite non-polluting source of energy that plays a major role in saving the diminishing fossil fuel reserves and substantially cutting greenhouse gases. However, the initial cost of materials and the relatively low efficiency increase the price per kilowatt hour of the generated electricity, which acts as an obstacle against the global propagation of most types of renewable energy systems. Solar trackers can be used to overcome this obstacle by increasing the efficiency and maximising the energy gain of a solar system throughout the day. In this study, a novel cost-effective, power-saving and extremely accurate Two-Axis Solar Tracking System was designed, built and examined in real-time operation under various test conditions. The tracker was installed on a specially fabricated Parabolic Trough Collector (PTC) with a unique structural design that allows both vertical and horizontal orientations. The PTC underwent testing under two conditions; fixed and under Two-Axis Solar Tracking control. In both conditions, the tests were performed under flow and no-flow states. The Two-Axis Tracking was exceptionally accurate and precise with smooth slow-motion orientation throughout the day. The test measurements were very convenient compared to the size of the parabola. The design proved to offer a significant boost in the overall energy gain of the collector.
\end{abstract}

\section{Introduction}

The Sun travels across the sky from the time it rises until the time it sets. The position of the Sun is a key factor in the performance of solar energy systems as it can immensely reduce the collector's energy gain by different ratios, depending on the type of the application. This energy loss can be overcome by the use of a solar tracking system that can ensure that maximum energy is constantly and persistently harvested by accurately orienting the solar panel towards the Sun.

Although the Sun irradiance at its origin is about $63 \mathrm{MW} / \mathrm{m}^{2}$, the solar energy flow on Earth's surface is approximately 1 $\mathrm{KW} / \mathrm{m}^{2}$ [1], this immense decrease is due to the Sun-Earth geometry. Sunlight is composed of two constituents; direct beam and diffuse sunlight. Ninety percent of the solar energy is conveyed by direct beam radiation while the remaining portion is conveyed by diffuse sunlight [2]. Non-concentrating solar collectors accept both direct and diffuse light. However, concentrating solar collectors only accept the direct beam portion since the energy produced is directly proportional to the reflected direct beam radiation that successfully hits its focal line/point. This makes the solar tracking system more essential in concentrating solar plants because unless directly pointed at the Sun they produce a negligible amount of energy.

\section{Tracking System}

\subsection{Overview}

The designed tracking system offers an efficient cost-wise competitive solution for maximising the total energy gain of concentrating and non-concentrating solar plants. A high-level overview of the tracking system is shown in Figure 1. The advantages of the designed tracking system are listed below.

1) It has the ability to track the Sun constantly and precisely regardless of the transition irregularity and the dependence on latitude, time of day or even the time of year.

2) It does not require any historical sun path data or any weather broadcast data and can be installed in any location without any prior adjustments.

3) It enables the user to switch between manual control, twoaxis automatic tracking and one-axis automatic tracking.

4) It does not require regular maintenance and can withstand harsh environmental high-temperature conditions.

5) It has the lowest cost in the market as it does not need any expensive computers or image processing devices.

6) It is suitable for all concentrating and non-concentrating solar applications, unlike most solar trackers.

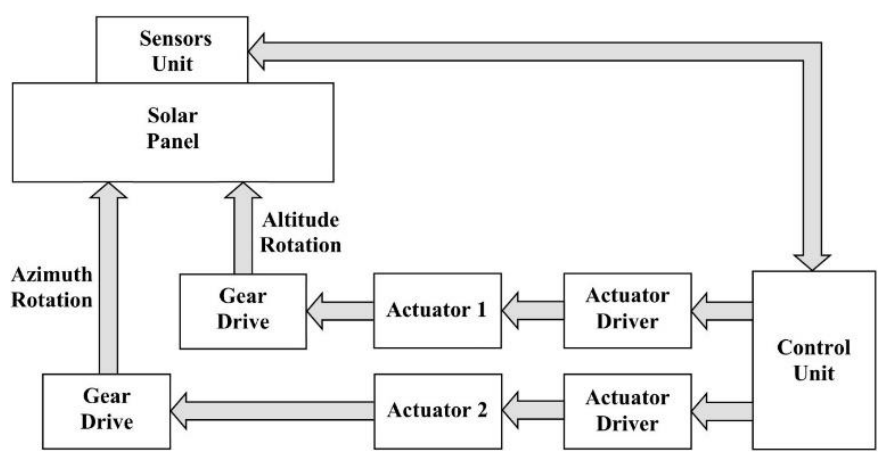

Figure 1: Tracking System Block Diagram 


\subsection{Light Intensity Sensor}

The developed tracker uses two pairs of Light Dependent Resistors (LDRs) to track the Sunlight. The LDR is a light intensity sensor that has the ability to change its electrical resistance $\left(R_{L D R}\right)$ according to the light intensity that strikes its surface. Four premium high-quality cadmium-sulphide LDRs were used as they provide highly accurate results with a spectral response similar to that of the human eye. Each LDR is encapsulated in a robust plastic casing, to ensure reliable operation under harsh environmental circumstances, and coated with a clear moisture-resistant substance that allows the light to reach its active surface (see Figure 2).
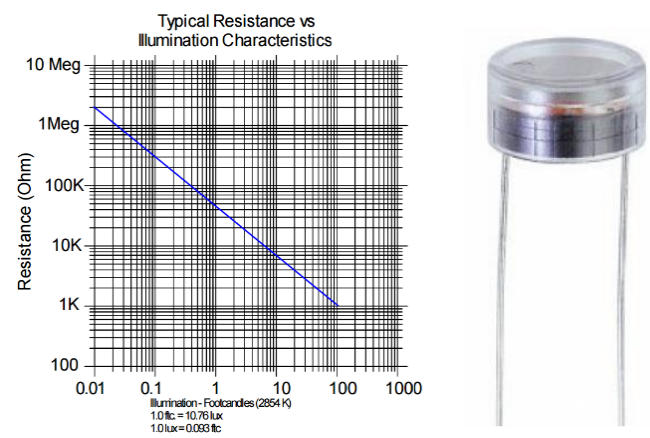

Figure 2: Resistance vs illumination characteristics

\subsection{The Sensors Unit}

Each LDR individually gives extremely precise results. However, the resistance of different LDRs may slightly vary under uniform light due to their inconsistent nature. These slight differences have been overcome by a unique resistive circuit that consists of a number of fixed resistors and highprecision, ten-turn counting rotary dial, potentiometers. The four LDRs were tested under various light conditions from 20 distant angles using a light torch. The test measurements were then used to equalise the resistance output of the four LDRs by adjusting the potentiometers. As shown in Figure 3, the four LDRs were mounted equidistantly in a cross-shaped orientation and separated by two perpendicular wooden rectangles; designed to create a natural shading effect on each LDR to form a wider resistance variation between each pair when the Sun travels a trivial distance.

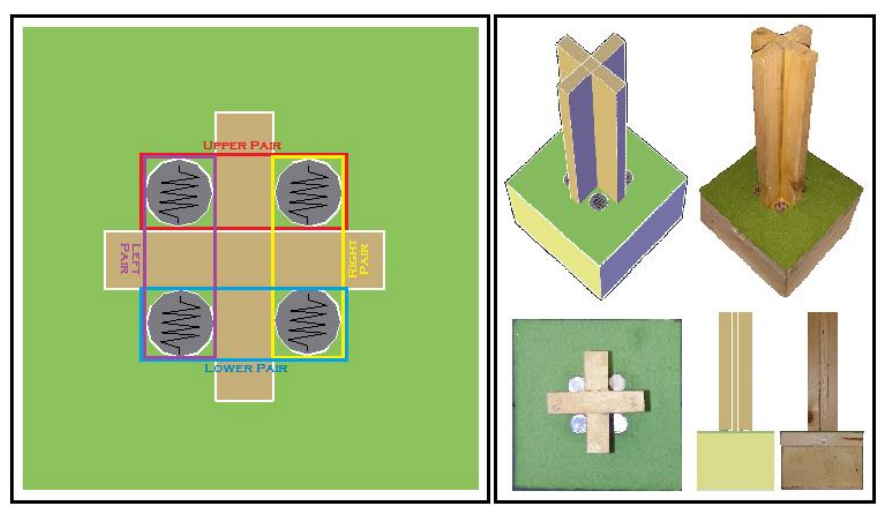

Figure 3: Sensors Unit

\subsection{The Control Unit}

\subsection{Data Analysis}

By applying a voltage $\left(V_{i n}\right)$ across the sensors resistive circuit, the output voltages $\left(V_{\text {out }}\right)$ fluctuate according to the changes in resistance of each LDR $\left(R_{L D R}\right)$ that are caused by light intensity deviations. This is expressed by the voltage divider formula shown below,

$$
V_{\text {out }}=V_{\text {in }} \frac{R_{\text {Resistors }}}{R_{\text {Resistors }}+R_{L D R}}
$$

Each analogue output voltage $\left(V_{\text {out }}\right)$ is constantly sent to a microcontroller (MCU) which automatically converts the incoming analogue voltage inputs $(0 \mathrm{~V}-5 \mathrm{~V})$ to digital values (0-1024) by using its built-in Analogue to Digital Converter (ADC). The MCU analyses this data and calculates the voltage value of the right, left, upper and lower pairs constantly. The voltage output difference between both the right and the left pairs and both the upper and the lower pairs are then compared to a selected tolerance. If the difference between the pairs exceeds the selected tolerance, the MCU sends signals to the actuators, with the aid of the actuators' drivers, to move the solar panel in the correlated direction. The tolerance value $(T)$ is set by default to 80 digital steps, however, it can be easily changed by the user depending on the user's requirements. The tracking system flowchart is shown in Figure 4.

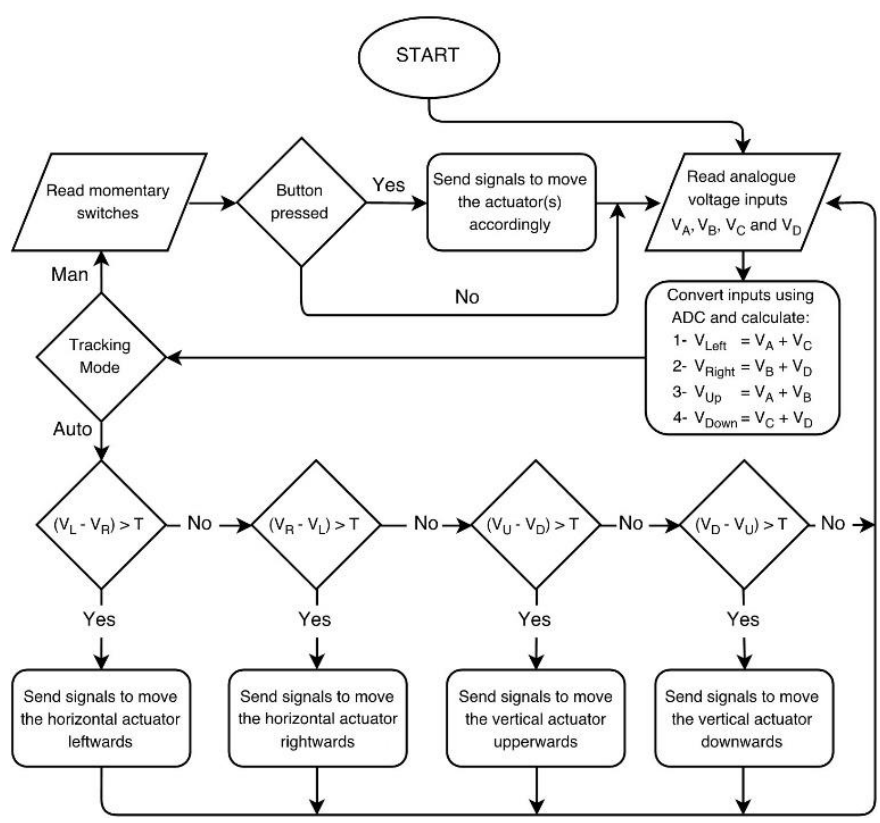

Figure 4: Tracking System Flowchart

\subsection{Simulation}

The Tracking System was simulated using Proteus Professional simulation software (see Figure 5). The simulation was performed on both manual and automatic control. The automatic control was tested by increasing and decreasing the light intensity on each LDR. The manual control 
and the motors were tested by pressing the on-screen push buttons. The responses were then observed and verified on both the LCD screen and the MCU ports.

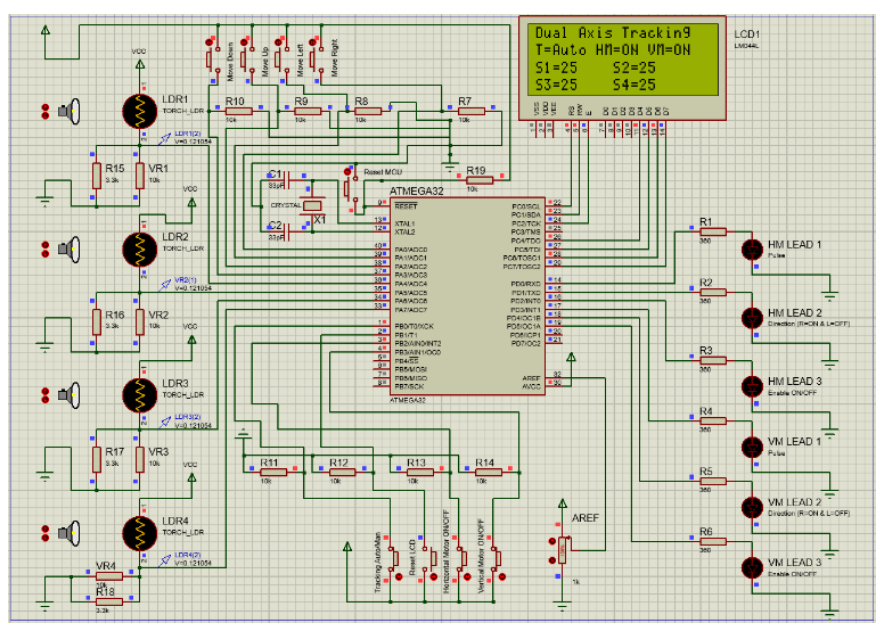

Figure 5: Tracking System Simulation

\subsection{User Interface}

The control unit has a built-in low-power consumption LCD screen that continuously displays the values of the four LDRs, the tracking mode (Auto/Man) and motors state (On/Off). The readings on the LCD are updated every $400 \mathrm{~ms}$ which represents the time taken for sampling.
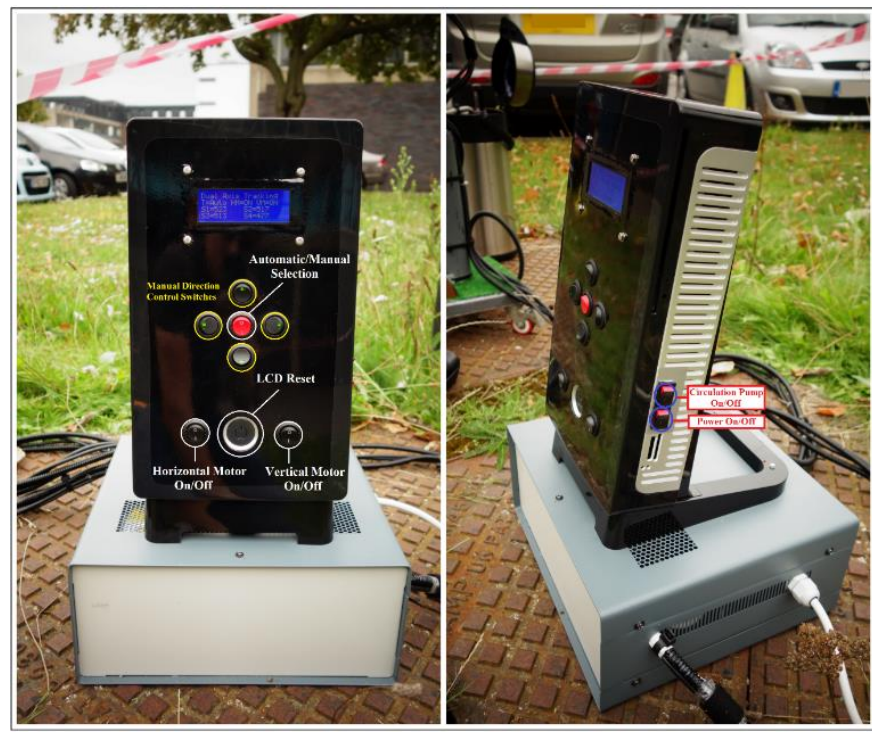

Figure 6: Control Unit

As shown in Figure 6, using the panel switches, the user can turn the control unit On/Off, turn the fluid circulation pump (if available) On/Off and select either automatic or manual control. If manual mode is selected, the user can freely move the solar panel in all directions. If automatic mode is selected, the user can turn any of the motors On/Off to select between two-axis (Azimuth and Altitude) tracking and one-axis (Azimuth or Altitude) tracking.

\section{Parabolic Trough}

\subsection{Overview}

Parabolic Troughs are concentrating solar thermal energy collectors. Parabolic concentrators aim to focus the direct solar radiation beams, which strike the reflector surface, onto a focal line. Fluid gets extensively heated as it is pumped through the absorber tube, which is placed across the focal line. The heated fluid can then be used in various technologies such as domestic appliances, industrial applications and electrical power generation plants.

\subsection{Parabolic Trough Design}

The Parabolic Trough Collector (PTC) was specially designed and constructed to allow dual-axis movement (see Figure 7). The design has two ball bearings in the main support column (for horizontal movement) and two pillow bearings in the secondary support column (for vertical movement). Two stepper motors are used, one that provides the horizontal movement with the aid of a pair of spur gears, while the other provides the vertical movement with the aid of a pair of bevel gears. Additionally, in order to perform a flow test, a fluid circulation system was implemented.

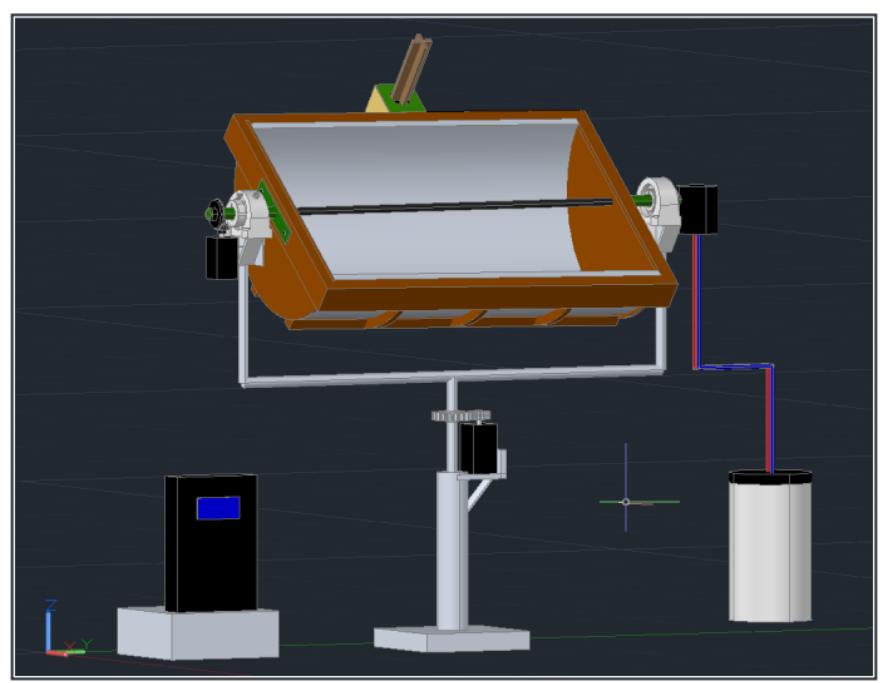

Figure 7: Parabolic Trough Design

\subsection{The Parabola}

A parabola consists of numerous points that are halfway between a focus point and a fixed line known as the directrix. The directrix is represented by the equation $y=-1$. Hence, a general point on the directrix can by given the coordinates $(x,-1)$. The distance formula is represented by,

$$
(x-0)^{2}+(y-1)^{2}=(x-x)^{2}+(y-(-1))^{2}
$$

Expanding the above expression yields,

$$
x^{2}+y^{2}-2 y+1=y^{2}+2 y+1
$$


Simplifying Equation (3), knowing that the vertex of this parabola is its origin, yields,

$$
y=\frac{x^{2}}{4 f}
$$

Where $f$ is the focal length of the parabola; the distance between the vertex and the focal point. The $y$ values are obtained by substituting incremental values of $x$ into Equation (4) while setting the focal point at the required value in order to construct the parabola design coordinates.

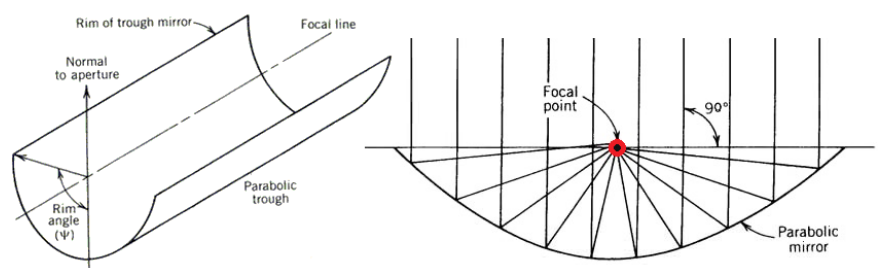

Figure 8: Parabola Design Factors

As shown in Figure 8 , the rim angle $\left(\psi_{\text {rim }}\right)$ is the angle between the normal to aperture line and the line connecting the focal line to the mirror edge. The rim angle has exceptional characteristics that allow it to be the sole determinant of the shape of the cross-section of a PTC; thus, PTCs with the same rim angles have geometrically alike cross-sections. In this design, the rim angle is selected to be 90 degrees, which means that the focal point is in-line with the two ends of the parabolic sheet. This mainly eases the construction and lowers the cost of the Parabolic Trough.

\subsection{The Reflector}

A siliverised polymer ReflecTech film with a reflectivity of 94\% was used. It has several advantages when compared to the market leading Flabeg Reflector. The first advantage is that it is durable in outdoor applications, abrasion resistant and can never shatter like glass reflectors and damage the system. The second is that it is made of a low-cost, ultra-lightweight and self-adhesive material that allows easy application. Moreover, it is made with unique properties specific for concentrating applications. Last but not least, it can be cleaned by brushless pressure washing using deionised or demineralised water. A high-strength $2 \mathrm{~mm}$ thick aluminium 7075-T6 sheet was curved/formed to match the parabola $x-y$ dimensions and the ReflecTech mirror film was then applied to the sheet.

\subsection{The Back Support}

The aluminium 7075-T6 offers an extremely high ultimate tensile strength value of $565 \mathrm{MPa}$, despite that, in very high wind speeds, a back support is essential. The support aims to inhibit any deformation that may occur, which would result in a huge amount of energy loss. The back support is made of lightweight wood, coated with epoxy and exterior varnish to prevent swelling and shrinking of the wood and to protect it from moisture and other harmful environmental factors.

\subsection{The Receiver}

A unique specially designed thermally efficient Varisol (® receiver was utilised. It has a minimum operating slope of $0^{\circ}$ which makes it ideal for PTCs. The Varisol receiver is characterised by its high absorption and low heat loss.

\begin{tabular}{|l|c|c|}
\hline Parameter & Value & Unit \\
\hline Absorptance & 95 & $\%$ \\
\hline Emissivity & 5 & $\%$ \\
\hline Tube Diameter & 10 & $\mathrm{~mm}$ \\
\hline Tube Weight & 1050 & $\mathrm{gm}$ \\
\hline Max Operating Temperature & 286 & ${ }^{\circ} \mathrm{C}$ \\
\hline Max Operating Pressure & 8 & Bar \\
\hline Max Fluid Flow Rate & 0.1 & $\mathrm{~L} / \mathrm{min}$ \\
\hline Max Fluid Velocity & 0.5 & $\mathrm{~m} / \mathrm{s}$ \\
\hline Fluid Capacity & 0.0078 & Litres \\
\hline Fluid Type & Water/glycol & - \\
\hline
\end{tabular}

Table 1: Varisol DF Properties

The receiver's efficiency drops significantly with very high temperatures. Therefore, it is not recommended for bigger parabolic concentrators with temperatures exceeding $286^{\circ} \mathrm{C}$.

\subsection{Concentration Ratio}

The concentration ratio $(C)$ is a fundamental factor in determining the service temperature range of concentrating power plants. It is the ratio of the radiant flux concentration at the focal line/point, known as the image of the Sun $\left(G_{i m}\right)$, to the direct irradiance at the collector's aperture $\left(G_{b, a p}\right)$ [3].

$$
C=\frac{G_{i m}}{G_{b, a p}}
$$

An appropriate approximation for Equation (5) is the geometrical concentration ratio $\left(C_{G}\right)$. It is the ratio of the collector's aperture area $\left(A_{a p, c}\right)$ to the receiver's aperture area $\left(A_{a p, r}\right)$.

$$
C_{G}=\frac{A_{a p, c}}{A_{a p, r}}=\frac{a \cdot l}{\pi \cdot \mathrm{d} \cdot l}=\frac{a}{\pi \cdot \mathrm{d}}
$$

\subsection{Fluid Circulation}

The fluid is circulated, between the receiver and a double walled vacuum insulated vessel, in a closed cycle system with the aid of an immersible high-temperature centrifugal brushless pump. The receiver has two copper tubes, one inside the other. The pump pressures the fluid into the smaller inner tube. As the fluid reaches the far end, it escapes to the outer tube where it absorbs the sunlight heat and gets circulated back to the storage vessel.

The copper pipe connections were welded and secured by a high-temperature silicon sealant and the fluid circulation system was pressured and tested at 1 bar. 


\section{Results and Analysis}

\subsection{Overview}

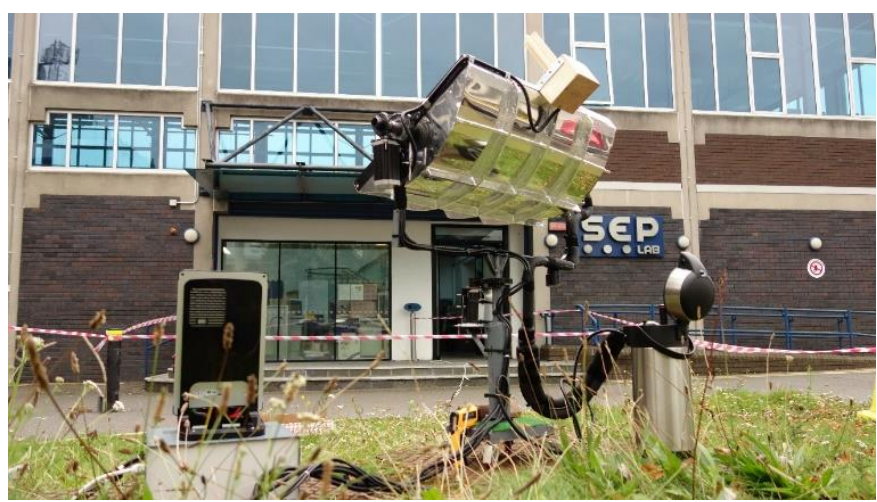

Figure 9: PTC with Two-Axis Tracking Assembly

Several tests were performed on the constructed Parabolic Trough to evaluate the effectiveness and performance of the solar tracking system. Throughout the testing stages, environmental conditions such as humidity, wind, ambient temperature, clouds and solar radiation were slightly fluctuating. However, neither the results nor its analysis was affected by these slight changes. The system was examined in real-time operation under the four different conditions shown in Table 2 below.

\begin{tabular}{|c|c|c|c|}
\hline Test & Tracking & Fluid Circulation & Flow Rate (Litre/min) \\
\hline A & 2-Axis & No Flow & 0 \\
B & Fixed & No Flow & 0 \\
C & 2-Axis & Flow & 0.05 \\
D & Fixed & Flow & 0.05 \\
\hline
\end{tabular}

Table 2: Real-Time Tests.

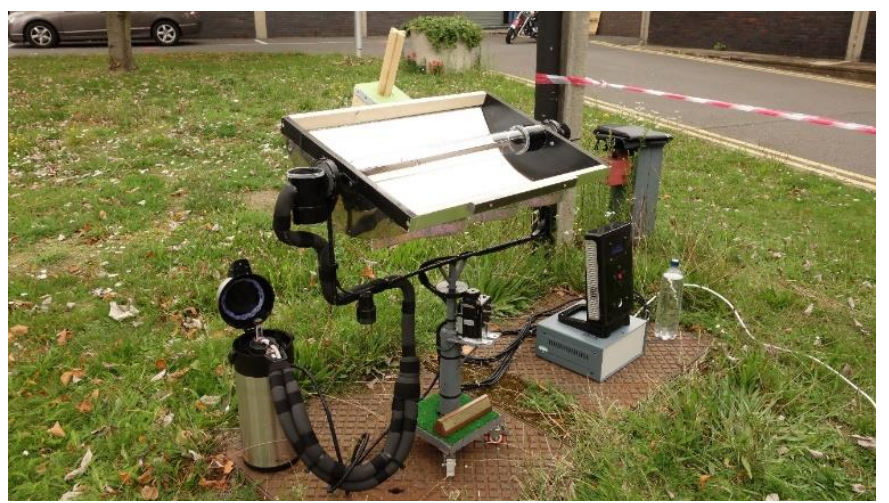

Figure 10: Real-Time tests on site

The four tests took place at Brunel University London in the Sustainable Electrical Power (SEP) Lab area. On each test, temperature measurements of the receiver and the water vessel were collected and recorded from 10:00 till 16:00 with 15 minute time intervals.

\subsection{Test Results}

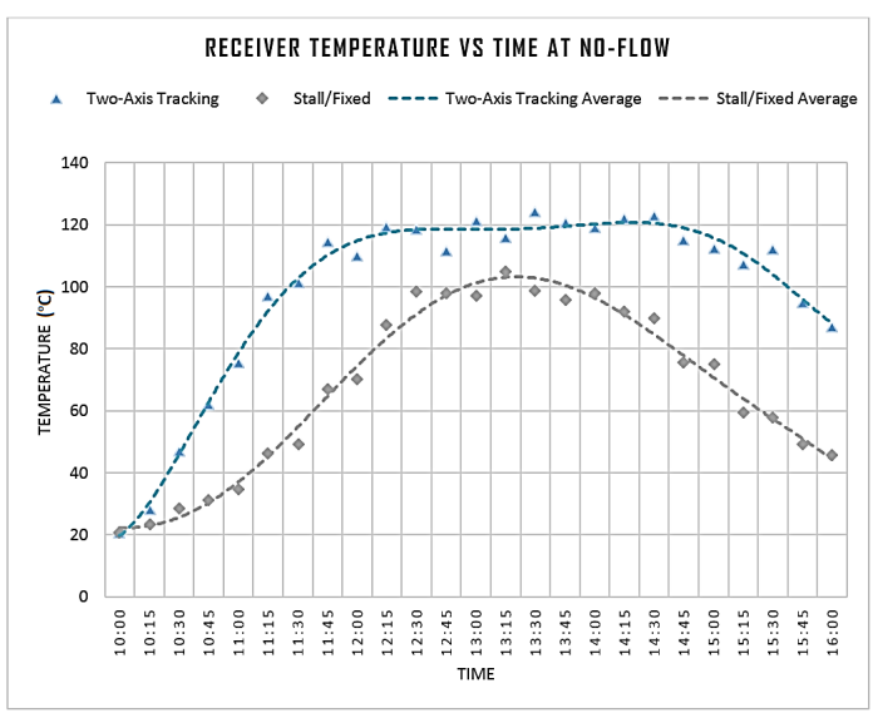

Figure 11: No-Flow Results (Test A and B)

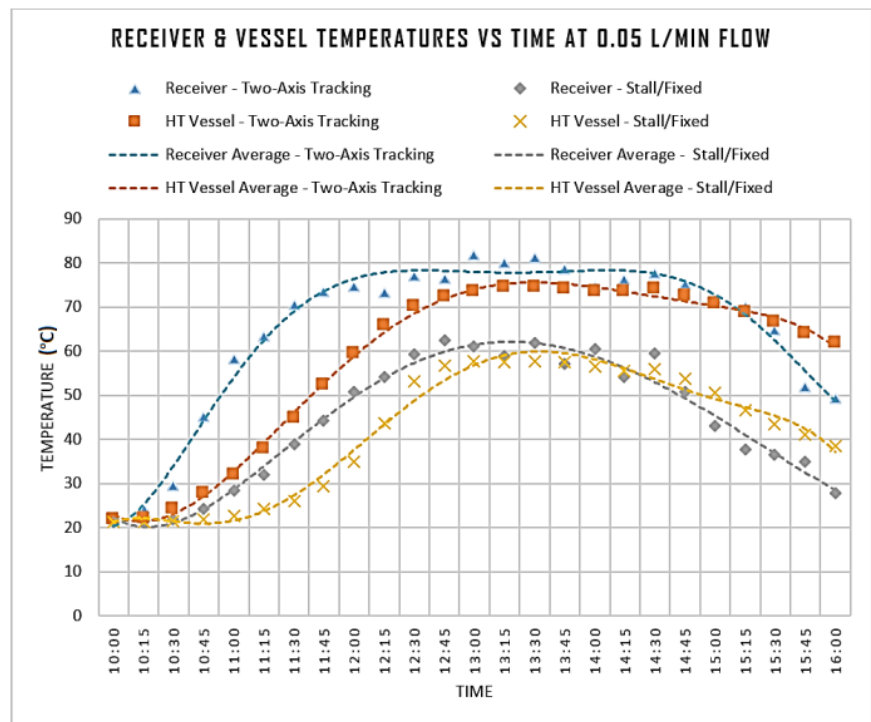

Figure 12: Flow Results (Test C and D)

\subsection{Analysis}

The test results, represented in Figure 11 and 12, show that there was a wide temperature difference between the Two-Axis Solar Tracking and Fixed modes throughout the day. This difference is observed to be greater at sunrise and sunset and least at noon (see Figure 13).

The intensity of direct irradiance is a function of cosine the angle of incidence $\left(\theta_{i}\right)$ being at its utmost at $\theta_{i}=0^{\circ}$ and at its bottommost at $\theta_{i}=90^{\circ}$. A rapid degradation of reflectance, and thus energy gain, occurs as the angle of incidence exceeds $50^{\circ}$. The angle of incidence during the Two-Axis Tracking tests was stabilised at approximately $0^{\circ}$. However, during the Stall/Fixed tests, the angle of incidence was varying according to the Sun's position which resulted in a massive energy loss. 
It was also visually observed that during the Stall/Fixed tests, some areas on the reflector sheet were shaded. This verifies that the implementation of a solar tracking system is significantly advantageous.

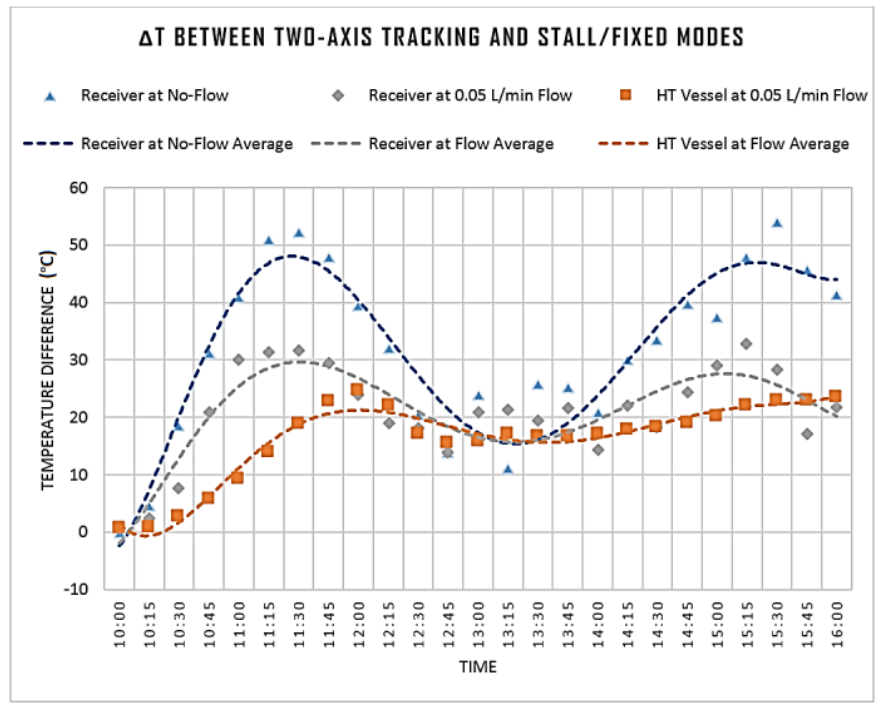

Figure 13: Temperature difference $(\Delta T)$

The average temperature differences of the Receiver $\left(\Delta T_{R \text { avg }}\right)$ between the two modes are $20.822^{\circ} \mathrm{C}$ and $31.5384^{\circ} \mathrm{C}$, during the Flow and the No-Flow tests respectively. While the average temperature difference of the HT Vessel $\left(\Delta T_{V \text { avg }}\right)$ during the Flow test is $16.17^{\circ} \mathrm{C}$ (calculated from the graph in Figure 13).

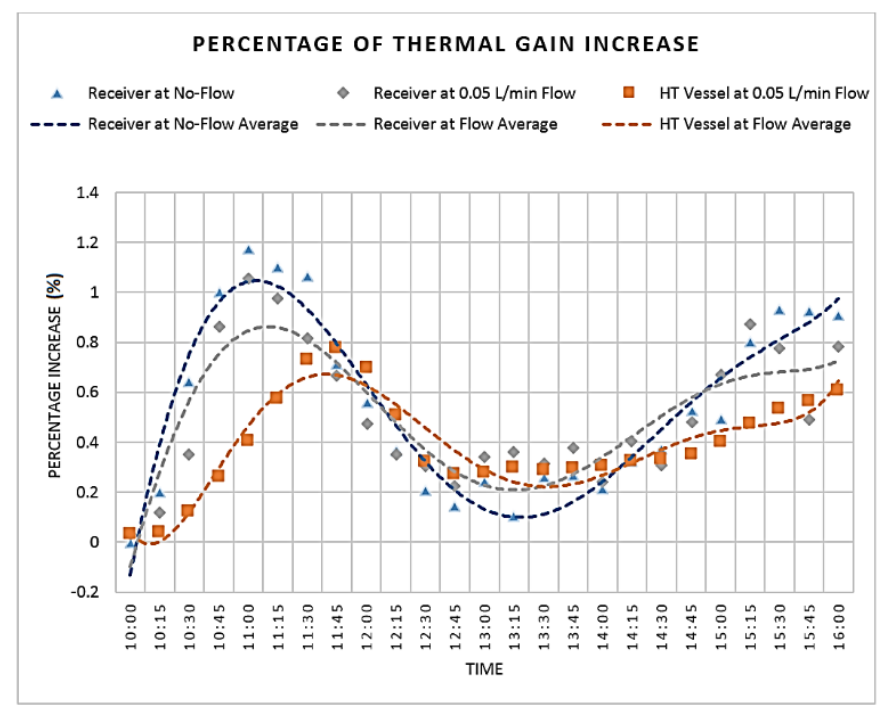

Figure 14: Percentage of Thermal Gain Increase

The average percentage of the thermal gain increase of the Receiver with the implementation of the Two-Axis Tracking is $50.59 \%$ during the Flow Test and 54.25\% during the No-Flow test. While the average percentage of the thermal gain increase of the HT Vessel during the Flow Test is $39.05 \%$. It is also noticeable that the percentage of thermal gain reaches its utmost before and after noon (see Figure 14).

\section{Cost Analysis}

\begin{tabular}{|l|c|}
\hline Item Description & Price \\
\hline Atmega32A-PU AVR 8-bit Microcontroller & 4.2 \\
\hline 40 Pin Atmega32 MCU mount & 0.39 \\
\hline HD44780 20X4 Character LCD Module Display & 5.25 \\
\hline $\begin{array}{l}\text { 1A 3-Terminal LM7805 Positive Voltage } \\
\text { Regulator IC 5V with heat sink }\end{array}$ & 0.55 \\
\hline Encapsulated Light Dependant Resistor LDR & 4.8 \\
\hline 16MHz Clock Crystal & 0.1 \\
\hline Fixed and variable resistors & 9.19 \\
\hline Through-hole Capacitors & 1.18 \\
\hline 100x160mm single sided copper boards & 1.65 \\
\hline 12 Volts 5 Amperes AC/DC converter & 5.5 \\
\hline Two-leads on-board screw Connectors & 1.65 \\
\hline Pin Strip PCB straight Header Pins & 1.1 \\
\hline On-Board Reset Button & 0.1 \\
\hline RS Panel Rocker Switches & 9.99 \\
\hline Terminal Blocks and PCB jumpers & 2.52 \\
\hline 3-terminal Power Switch & 0.5 \\
\hline 1/2 metre square 0.5cm wood & 4.5 \\
\hline Total materials cost & $£ \mathbf{5 3 . 1 7}$ \\
\hline
\end{tabular}

Table 3: Solar Tracker Cost Analysis

When compared to other tracking system technologies, the fabricated solar tracker is characterised by being not only accurate and precise but also the cheapest in the market by far.

\section{Conclusions}

The tracking system employment is generally a trade-off between collector's efficiency and cost since it requires additional investments in tracking systems, additional gears, motors and, last but not least, structural adjustments. The results obtained prove that the Two-Tracking System attained a high percentage of thermal gain increase in both Flow and No-Flow conditions. This, in turn, increases the quantity of energy produced from an installed power plant and decreases the cost per kilowatt hour of electricity produced. Nevertheless, it must be mentioned that the percentage of thermal gain varies from one application to another, depending on the technique of harnessing the solar energy.

\section{References}

[1] S. A. Kalogirou. "Solar Thermal Collectors and Applications", Progress in Energy and Combustion Science, vol. 30, pp. 231-295, (2004).

[2] E. O. Falayin, A. B. Rabiu. "Solar Radiation Models and Information for Renewable Energy Applications" in Solar Radiation, Elisha B. Babatunde, Ed. InTech, DOI: 10.5772/35390, 2012, pp. 111-130.

[3] G. Coccia, G. Latini, M. Sotte. "Mathematical Modeling of a Prototype of Parabolic Trough Solar Collector", Journal of Renewable and Sustainable Energy, vol. 4, (2012). 